\title{
Outline of the 2011 off the Pacific coast of Tohoku Earthquake $\left(M_{\mathrm{w}} 9.0\right)$ -Seismicity: foreshocks, mainshock, aftershocks, and induced activity-
}

\author{
Fuyuki Hirose $^{1}$, Kazuki Miyaoka ${ }^{2}$, Naoki Hayashimoto $^{1}$, Takayuki Yamazaki ${ }^{3}$, and Masaki Nakamura ${ }^{2}$ \\ ${ }^{1}$ Seismology and Volcanology Research Department, Meteorological Research Institute, 1-1 Nagamine, Tsukuba, Ibaraki 305-0052, Japan \\ ${ }^{2}$ Japan Meteorological Agency, 1-3-4 Ohtemachi, Chiyoda-ku, Tokyo 100-8122, Japan \\ ${ }^{3}$ Matsushiro Seismological Observatory, 3511 Saijo, Matsushiro, Nagano, Nagano 381-1232, Japan
}

(Received April 10, 2011; Revised May 18, 2011; Accepted May 19, 2011; Online published September 27, 2011)

\begin{abstract}
A massive earthquake of a magnitude $(M)$ of 9.0 occurred on March 11, 2011, off the Pacific coast of the northeastern part of Honshu, Japan. Centroid Moment Tensor analysis of the mainshock indicates that it was the reverse fault type, with a WNW-ESE compressional axis. The earthquake occurred on the plate boundary between the island arc and the Pacific plates. Three aftershocks exceeding $M 7$ occurred within 40-min after the mainshock, and the aftershock area covered a wide range of $500-\mathrm{km} \times 200-\mathrm{km}$. Seismicity became active one month before the mainshock, and it continued for two weeks in an adjacent area northeast of the mainshock. Furthermore, foreshock activity with maximum $M 7.3$ started in the same area two days before the mainshock. Seismic activities increased in almost the entire area of the Japanese Islands after the mainshock. We infer that these earthquakes were induced by the mainshock. JMA displacement-amplitude magnitude of the mainshock was determined to be 8.4, which was smaller than the moment magnitude of 9.0.
\end{abstract}

Key words: Foreshock and aftershock, massive earthquake on the plate boundary, induced seismicity, northeastern Japan.

\section{Introduction}

We belong to the Japan Meteorological Agency (JMA) which determines routinely the hypocenter, the magnitude, and the Centroid Moment Tensor (CMT) solution of each earthquake in and around Japan. JMA also has the naming rights for the great natural disaster. A massive earthquake of $M_{\mathrm{w}} 9.0$ occurred on March 11, 2011, off the Pacific coast of the northeastern part of Honshu, Japan. The earthquake caused a huge tsunami which killed more than 10,000 people. JMA named the earthquake "The 2011 off the Pacific coast of Tohoku Earthquake". In this paper, for the 2011 Tohoku Earthquake, we will report the fundamental information and features of seismicity which we estimated for foreshocks, the mainshock, aftershocks, and induced activity.

\section{Method for Estimating Parameters}

We determine hypocenters using the arrival times of $P$ wave and $S$-wave at seismic stations in Japan. Iterative method (Hamada et al., 1983) is used to calculate hypocenters by taking into consideration the data weight related to the hypocentral distance (Ueno et al., 2002).

Magnitudes are calculated from the maximum seismic wave amplitudes. The displacement magnitude $\left(M_{\mathrm{D}}\right)$ is adopted to be an official magnitude of JMA, $M_{\mathrm{J}}$, for relatively large earthquakes (Katsumata, 2004), and the ve-

Copyright (C) The Society of Geomagnetism and Earth, Planetary and Space Sciences (SGEPSS); The Seismological Society of Japan; The Volcanological Society of Japan; The Geodetic Society of Japan; The Japanese Society for Planetary Sciences; TERRAPUB.

doi:10.5047/eps.2011.05.019 locity magnitude $\left(M_{\mathrm{V}}\right)$ is for relatively small earthquakes (Funasaki and Earthquake Prediction Information division, 2004). The $M_{\mathrm{D}}$ is determined from the maximum amplitudes of horizontal displacement record obtained with a filter of the period $6 \mathrm{~s}$ and the damping the factor 0.55 . The $M_{\mathrm{V}}$ is determined from the maximum amplitudes of vertical component. $M_{\mathrm{D}}$ is adopted as $M_{\mathrm{J}}$ only when $M_{\mathrm{D}}$ is able to be estimated. It is well known that $M_{\mathrm{J}}$ is almost the same as $M_{\mathrm{w}}$ up to around 8 on the average (Utsu, 1982; Katsumata, 2004). However, when a magnitude is more than $8, M_{\mathrm{J}}$ is not appropriate due to the saturation of amplitude-magnitude. $M_{\mathrm{w}}$ was adopted exceptionally for the official magnitude of the mainshock and the largest aftershock, although it was different from the official procedure, which will be explained in Sections 3.1 and 3.3. In this paper, both $M$ and $M_{\mathrm{J}}$ mean the official magnitude of JMA.

In JMA, the Centroid Moment Tensor (CMT) inversion analysis of earthquakes in and around Japan has been managed since 1994 using the broadband seismographs. The processing technique is based on the methods developed by Kawakatsu (1989). For further details, see Nakamura et al. (2003).

We applied the maximum likelihood estimation method (Aki, 1965) to estimate the $b$-value, which is a parameter in the Gutenberg-Richter's formula (Gutenberg and Richter, 1944), of aftershocks. We also estimated the $p$-value, which is a parameter related with the attenuation of aftershocks, by applying the modified Omori formula (Utsu, 1957) to earthquake data from the occurrence of the mainshock to March 31, 2011. 


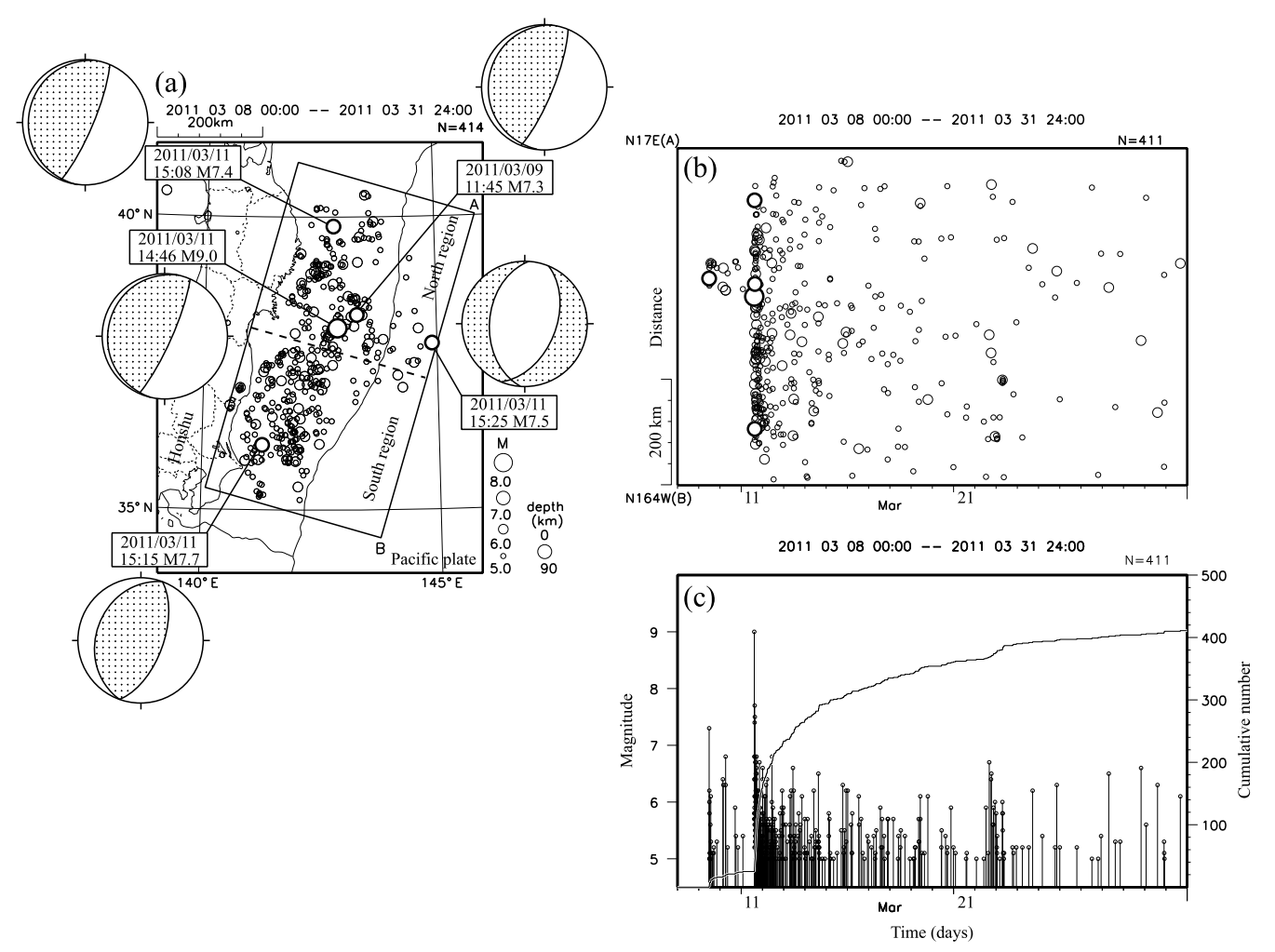

Fig. 1. (a) Epicenters of earthquakes off the Pacific coast of the northeastern part of Honshu, Japan with $M \geq 5.0$, depth $\leq 90-\mathrm{km}$ from Mar. 8, 2011 to Mar. 31, 2011. Origin times and magnitudes are noted for earthquakes of more than or equal to $M$ 7.0. Beach balls indicate CMT solutions with lower hemisphere of equal-area projection. As the aftershock area, we defined a 500-km $\times 200-\mathrm{km}$ rectangular area where earthquakes more than or equal to $M 5.0$ occurred within a week after the mainshock. (b) Spatial-temporal distribution of earthquakes within the rectangle along line A-B in (a). (c) Plot of magnitude and cumulative numbers of events versus time within the rectangle in (a).
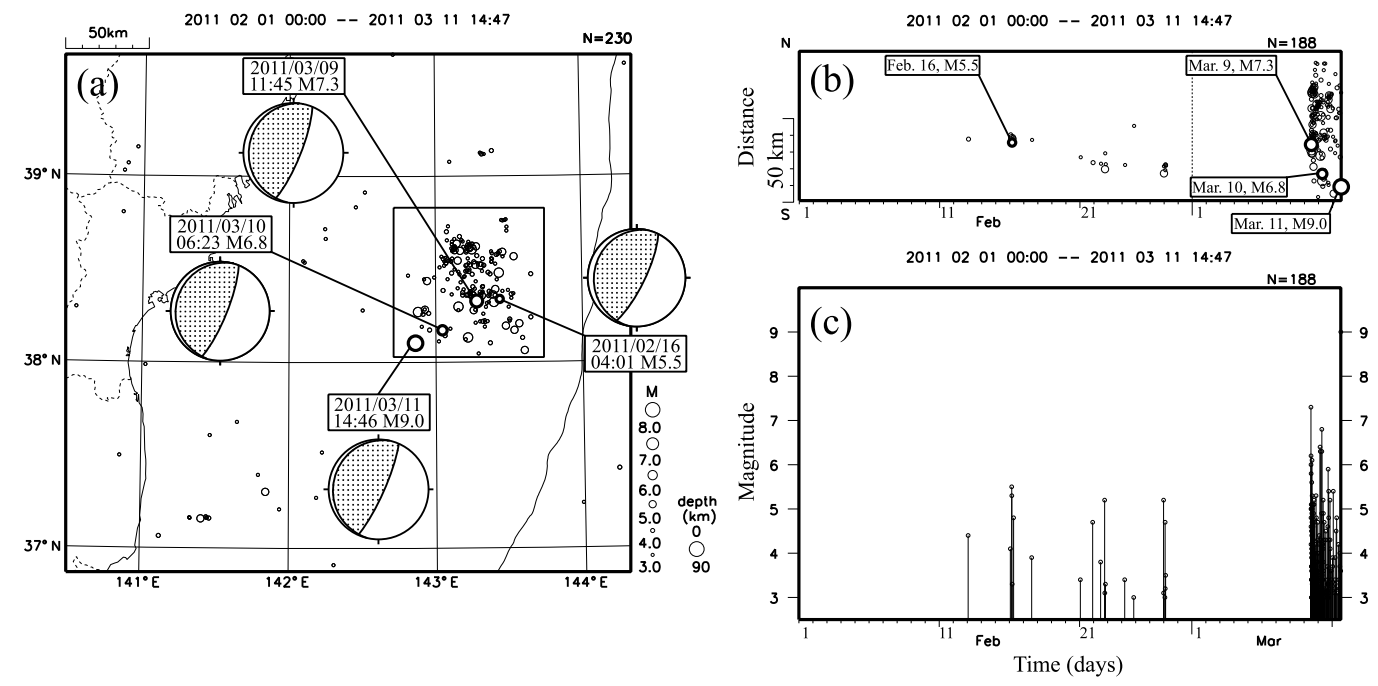

Fig. 2. (a) Epicentral distribution around the mainshock with $M \geq 3.0$ from Feb. 1, 2011 to the mainshock. (b) Spatial-temporal distribution and (c) $M-T$ diagram of earthquakes within the rectangle in (a).

\section{Features of Seismicity}

\subsection{Mainshock}

A massive $M_{\mathrm{w}} 9.0$ earthquake occurred at 14:46 JST (05:46 UTC) on Mar. 11, 2011, off the Pacific coast of the northeastern part of Honshu, Japan (Fig. 1). The CMT solution of the mainshock indicates a reverse fault type with a WNW-ESE compressional axis. The earthquake occurred on the plate boundary between the island arc and the $\mathrm{Pa}-$ cific plates. Results of source process analysis with local strong motion data (Yoshida et al., 2011) indicate that the area of the largest rupture was located in the northeast of the hypocenter, and that the maximum slip amounted to 25$\mathrm{m}$. This area is almost the same as the area of the largest rupture estimated by the source process analysis with teleseismic data (Yoshida et al., 2011). The rupture gradually extended around the hypocenter and propagated both southward and northward. For further details, see Yoshida et al. (2011). 

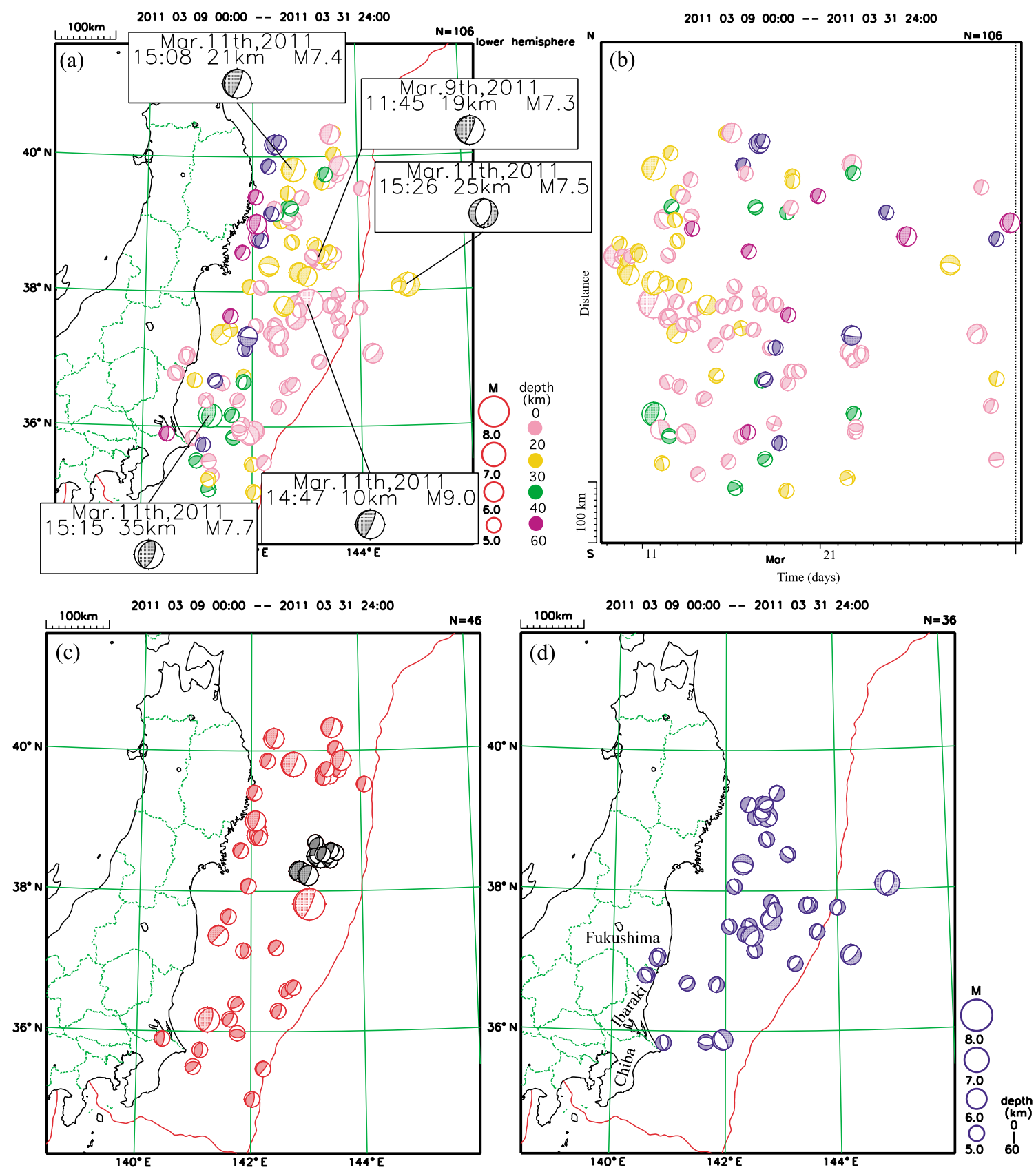

Fig. 3. (a) Spatial and (b) spatial-temporal distributions of focal mechanisms determined by CMT analysis. (c) Reverse and (d) normal fault type. The black in (c) indicates focal mechanism of the foreshocks.

$M_{\mathrm{D}}$ of this event was estimated at 8.4 while $M_{\mathrm{w}}$ was 9.0. This large difference between $M_{\mathrm{D}}$ and $M_{\mathrm{w}}$ results from the saturation of amplitude-magnitude. At first, $M_{\mathrm{w}}$ was estimated at 8.8 by CMT analysis using a filter of 100-300 s for 30-min teleseismic data. And then, $M_{\mathrm{w}}$ was revised to be 9.0 by CMT analysis using a filter of 200-1000 s for 50-min teleseismic data because the filter of 100-300 s and waveforms of 30-min are too short for the analysis of the event. Thus we adopted the value of moment magnitude of 9.0 exceptionally for the official magnitude of JMA with consideration also of the relation between the magnitude of the mainshock and the aftershock area (Utsu, 1961).

\subsection{Foreshocks}

Seismic activity, including $M 5.5$ event, started one month before the mainshock and continued for two weeks in an adjacent area $50-\mathrm{km}$ northeast from the epicenter of the mainshock (Fig. 2). Furthermore, the largest foreshock of M 7.3 (Mar. 11, 2011 11:45 JST) occurred in the same area two days before the $M 9$ mainshock. The foreshock area spread around the epicenter of the $M 9$ mainshock. These earthquakes were interplate earthquakes like the mainshock because the focal mechanisms determined by the CMT analysis also indicate a reverse fault type with a WNW-ESE compressional axis, which is the same as that of the mainshock. We assume that these sequential events for about one month were foreshocks because they occurred close to the mainshock both spatially and temporally.

\subsection{Aftershocks}

The aftershock area covered a wide range of $500-\mathrm{km} \times$ 200-km (Fig. 1), and aftershocks occurred at an edge of the 


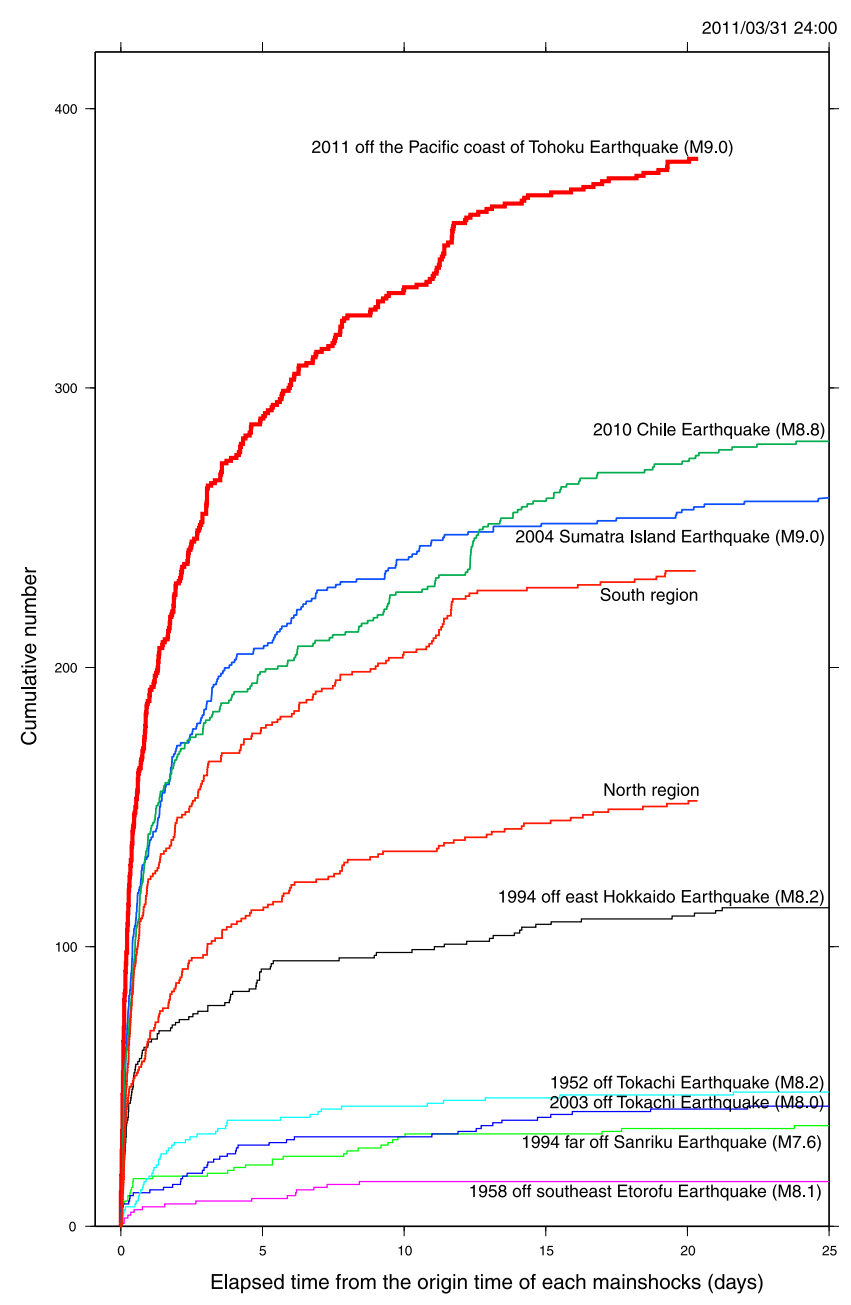

Fig. 4. Plot of cumulative numbers of aftershocks of more than or equal to $M 5.0$ versus time for various events in Japan, in addition to the 2004 Sumatra and 2010 Chile earthquakes. As the aftershock area of several mainshocks, we defined an area where earthquakes more than or equal to $M 5.0$ occurred within a week after the mainshock. The horizontal axis denotes elapsed time after the origin time of each mainshock. Two thin red lines indicate aftershocks in north and south regions in Fig. 1(a).

relatively large slip area of the mainshock (Yoshida et al., 2011). Three aftershocks of $M \sim 7$ occurred successively within 40-min after the mainshock. Among them, the focal mechanisms of the $M 7.4$ and $M 7.7$ events indicate a reverse fault type like the mainshock. $M_{\mathrm{w}}$ of the aftershock which occurred off Ibaraki was estimated to be 7.7 by CMT analysis using a filter of 45-200 s for 10-min local data while $M_{\mathrm{D}}$ was 7.4. The difference between $M_{\mathrm{D}}$ and $M_{\mathrm{w}}$ is very large. We compared seismic waveforms of this aftershock event with those of the largest foreshock $\left(M_{\mathrm{J}} 7.3\right.$, $M_{\mathrm{w}} 7.3$ ) because $M_{\mathrm{D}}$ of the two events is similar. As the result, we found that $M_{\mathrm{w}}$ of the aftershock was larger than $M_{\mathrm{D}}$ because long-period components of waveforms used by CMT analysis of the aftershock were more prominent than that of the largest foreshock. We also checked $M_{\mathrm{w}}$ estimated by the U.S. Geological Survey (USGS) and confirmed that both $M_{\mathrm{w}}$ were the almost same. Thus we adopted the value of 7.7 exceptionally for the official magnitude. A M 7.5 aftershock occurred beneath the outer rise, and the focal mechanism of this event indicates a normal fault type.

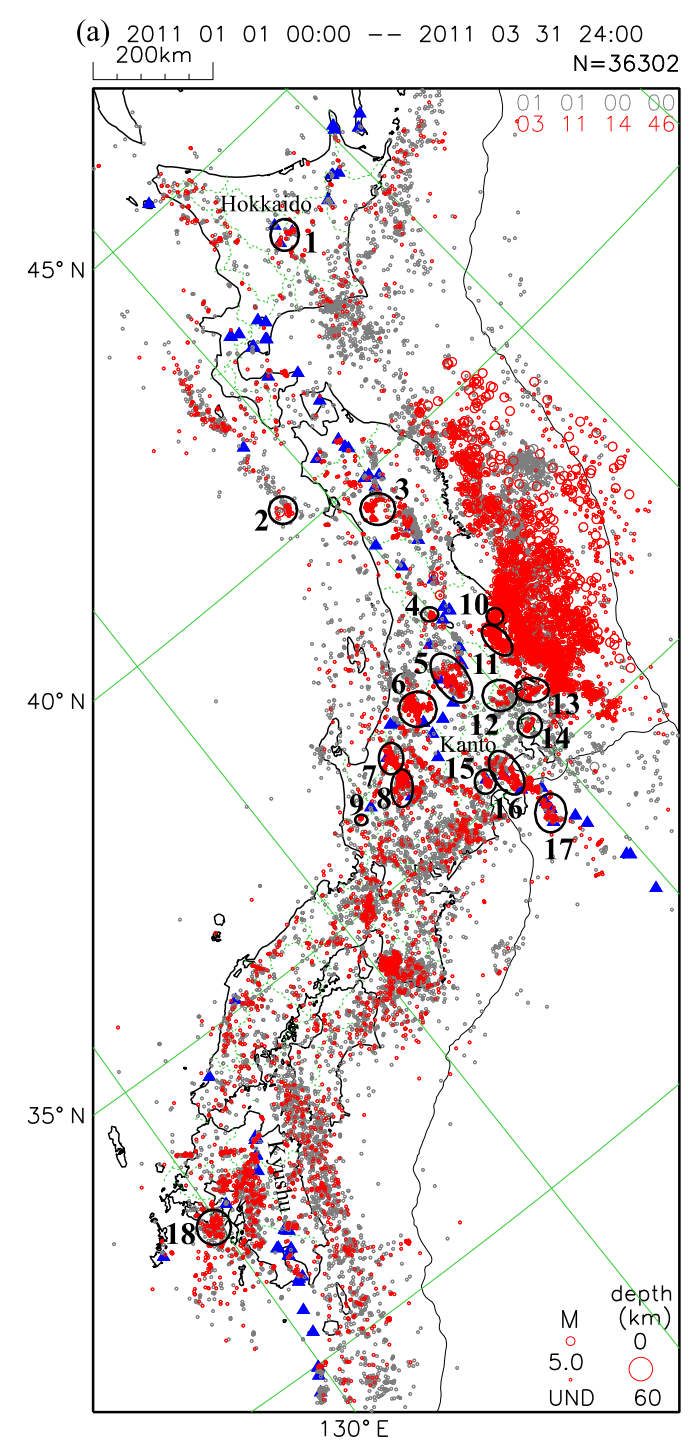

Fig. 5. (a) Epicentral distribution in and around Japan at a depth $\leq$ 60-km from Jan. 1, 2011 to Mar. 31, 2011. Red symbols indicate events that occurred after 14:46 on Mar. 11, 2011. (b-s) Plots of magnitude and cumulative numbers of events versus time within each ellipse in (a). Broken lines indicate the origin time of the $M_{\mathrm{w}} 9.0$ mainshock. The starting time of induced seismicity and the origin time of an event with a maximum magnitude are shown in each panel. Note that hypocenter determination processing by JMA cannot keep up with quasi-real time processing (as of 2011/03/31) because too many aftershocks and induced earthquakes occurred. Therefore, for example, sparse seismicity in regions $5,7,8,9,12,13$ and 14 to be seen in almost the same timing after the $M_{\mathrm{w}} 9.0$ mainshock is not natural but artificial.

Figure 3 depicts the spatial and spatial-temporal distributions of focal mechanisms determined by CMT analysis. Many earthquakes of the normal fault type have occurred as well as the reverse fault type. The events of the reverse fault type were distributed over the whole aftershock area except the area with large slip, whereas those of the normal fault type were distributed in the central part of the aftershock area. It is noted that the normal fault type events occurred near the Japan Trench and land area.

Figure 4 presents cumulative numbers of aftershock events of $M \geq 5.0$ versus the elapsed time after the origin of several large events in and around Japan, Sumatra Island (Dec. 26, 2004; $M_{\mathrm{w}}$ 9.0), and Chile (Feb. 27, 2010; $M_{\mathrm{w}} 8.8$ ). 

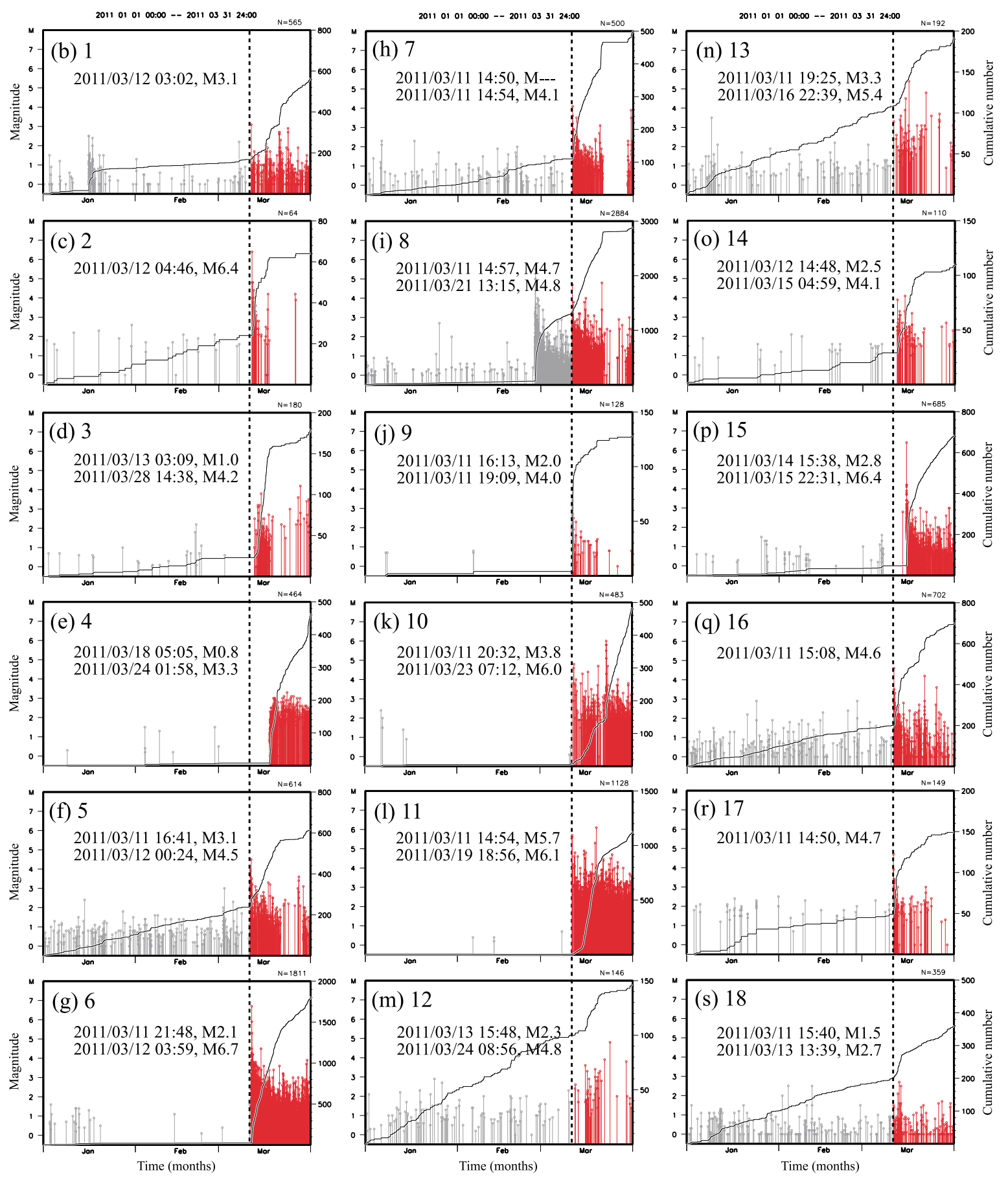

Fig. 5. (continued).

We used the Preliminary Determination of Epicenters of the USGS for aftershock of the 2004 Sumatra and 2010 Chile earthquakes. Aftershocks of the 2011 Tohoku Earthquake are more active than those of the 2004 Sumatra and 2010 Chile earthquakes of almost the same magnitude. Numerous aftershocks have occurred especially in the southern part of the aftershock area (Fig. 4). A $p$-value of 1.05 and a $b$-value of 0.78 were estimated for the aftershock of the 2011 Tohoku Earthquake by using events with $M \geq 5.0 \mathrm{im}-$ mediately after the mainshock until Mar. 31, 2011. Hosono (2006) had estimated the parameters for many aftershock activities in Japan. The estimated $p$-value ranged from 0.78 to 1.38 , and its median was 0.93 . The estimated $b$-value ranged from 0.46 to 0.92 , and its median was 0.64 . These were estimated from 8 mainshock-aftershock sequences in northeastern Japan. The parameters for the aftershock of the 2011 Tohoku Earthquake are larger than the medians.

\subsection{Induced activity}

Seismic activities increased in and around Japan after the mainshock. Figure 5 indicates the change of activity before and after the mainshock, and each elliptical area indicates an activated area after the mainshock. Seismic activities in many areas of Japan, from Hokkaido to Kyushu, were increased. Among them, there were many activated areas in and around the Kanto district. Induced seismicity regions tend to be distributed along the volcanic front. Seismic- 
ity in regions $7,8,11,16$, and 17 in Fig. 5 became active immediately after the $M_{\mathrm{w}} 9.0$ mainshock occurred at 14:46 on Mar. 11, 2011, while those in regions 4 and 15 became active more than 3 days after the mainshock. There is no regional bias for the starting time of the induced seismicity. The largest event occurred 3 hours to 15 days after the induced seismicity started in many regions except for regions $1,2,7,16$, and 17. Events of $M \geq 6.0$ occurred in regions $2,6,10,11$, and 15 . Most of the induced activity has remained active until the present (Mar. 31, 2011).

\section{Discussion}

Some aftershocks of the normal fault type occurred beneath the outer rise (Figs. 1(a), 3(d)). It is thought that normal fault type events occur under the influence of the slab bending (Seno and Gonzalez, 1987). In the present case, in addition, some aftershocks beneath the outer rise were induced by the east-west extension field made by the mainshock which released the compressional stress caused by the subduction of the Pacific plate.

Shallow earthquakes of the normal fault type near the Pacific coast in Fukushima, Ibaraki, and Chiba prefectures (Fig. 3(d)) would be "induced earthquakes" rather than "offfault aftershocks" although these events occurred in the aftershock area we defined. Here the term "off-fault aftershocks" implies descendants while the term "induced earthquakes" means others. It is thought that the shallow earthquakes shown in Fig. 5 were induced by both the dynamic effect due to the seismic wave of the mainshock and the static effect due to crustal deformation. For example, events in volcanic zones may be activated by the degassing reaction of the magma due to the seismic wave. In addition, the shallow earthquakes that occurred in the inland crust may also have been induced by the east-west extension field when the locked region of the plate boundary was slipped by the mainshock and its after-slip. We cannot predict terminations of activated seismicity at the present (Mar. 31, 2011), but, for example, seismicity in volcanic zones in the Hokkaido district induced by the Tokachi-oki earthquake in 2003 (M 8.0) continued for more than half a year (Japan Meteorological Agency, 2005).

\section{Summary}

A massive $M_{\mathrm{w}} 9.0$ earthquake occurred at 14:46 JST (05:46 UTC) on Mar. 11, 2011, off the Pacific coast of the northeastern part of Japan. The earthquake occurred on the plate boundary between the island arc and the Pacific plates. The focal mechanism of the mainshock indicates a reverse fault type with a WNW-ESE compressional axis. Three aftershocks exceeding $M 7$ class occurred within 40-min after the mainshock, and the aftershock area covered a wide range of $500-\mathrm{km} \times 200-\mathrm{km}$. The aftershocks of the 2011 Tohoku Earthquake are more active than those of the 2004 Sumatra and 2010 Chile earthquakes. Seismic activity occurred one month before the mainshock in an adjacent area northeast of the mainshock, and it continued for two weeks. Furthermore, the largest foreshock of $M 7.3$ occurred in the same area two days before the $M 9$ mainshock. The foreshock area spread around the epicenter of the $M 9$ mainshock. Seismic activities increased in almost all of Japan after the mainshock. We infer that these earthquakes were induced by both the dynamic effect of the seismic wave from the mainshock and the static effect of crustal deformation. We think that shallow earthquakes of the normal fault type that occurred in the inland crust as well as beneath the outer rise were induced by the east-west extension field resulting from the mainshock, which released compressional stress caused by the subduction of the Pacific plate.

Acknowledgments. We thank the institutions, universities, and JMA for providing the unified hypocenter catalog. This manuscript was greatly improved by the careful reviews of Dr. A. Hasemi and an anonymous reviewer. Figures were prepared using GMT (Wessel and Smith, 1991).

\section{References}

Aki, K., Maximum likelihood estimate of $\mathrm{b}$ in the formula $\log \mathrm{N}=\mathrm{a}-\mathrm{bM}$ and its confidence limits, Bull. Earthq. Res. Inst., 43, 237-239, 1965.

Funasaki, J. and Earthquake Prediction Information division, Revision of the JMA velocity magnitude, Quart. J. Seismol., 67, 11-20, 2004 (in Japanese with English abstract).

Gutenberg, B. and C. F. Richter, Frequency of earthquakes in California, Bull. Seismol. Soc. Am., 34, 185-188, 1944.

Hamada, N., A. Yoshida, and H. Hashimoto, Improvement of the hypocenter determination program of the Japan Meteorological Agency (Reanalyses of the hypocenter distribution of the 1980 Earthquake Swarm off the east coast of the Izu Peninsula and the Matsushiro Earthquake Swarm), Quart. J. Seismol., 48, 35-55, 1983 (in Japanese with English abstract).

Hosono, K., New standard parameters of aftershocks in Japan, Quart. J. Seismol., 69, 171-176, 2006 (in Japanese).

Japan Meteorological Agency, Report on the Tokachi-oki Earthquake in 2003, Technical Report of the Japan Meteorological Agency, 126, 228 pp., 2005 (in Japanese with English abstract).

Katsumata, A., Revision of the JMA displacement magnitude, Quart. J. Seismol., 67, 1-11, 2004 (in Japanese with English abstract).

Kawakatsu, H., Centroid single force inversion of seismic waves generated by landslides, J. Geophys. Res., 94, 12,363-12,374, 1989.

Nakamura, K., S. Aoki, and Y. Yoshida, Centroid moment tensor analysis by using the JMA broadband seismic observation network, Quart. J. Seismol., 66, 1-15, 2003 (in Japanese with English abstract).

Seno, T. and D. G. Gonzalez, Faulting caused by earthquakes beneath the outer slope of the Japan Trench, J. Phys. Earth, 35, 381-407, 1987.

Ueno, H., S. Hatakeyama, T. Aketagawa, J. Funasaki, and N. Hamada, Improvement of hypocenter determination procedures in the Japan Meteorological Agency, Quart.J. Seismol., 65, 123-134, 2002 (in Japanese with English abstract).

Utsu, T., Magnitude of earthquakes and occurrence of their aftershocks, J. Seismol. Soc. Jpn., 2(10), 35-45, 1957 (in Japanese with English abstract).

Utsu, T., A statistical study on the occurrence of aftershocks, Geophys. Mag., 30, 521-605, 1961.

Utsu, T., Relationships between earthquake magnitude scales, Bull. Earthq. Res. Inst., 57, 465-497, 1982.

Wessel, P. and W. H. F. Smith, Free software helps map and display data, Eos Trans. AGU, 72, 441, 1991.

Yoshida, Y., H. Ueno, D. Muto, and S. Aoki, Source process of the 2011 off the Pacific coast of Tohoku Earthquake with the combination of teleseismic and strong motion data, Earth Planets Space, 63, this issue, $565-569,2011$.

F. Hirose (e-mail: fhirose@mri-jma.go.jp), K. Miyaoka, N. Hayashimoto, T. Yamazaki, and M. Nakamura 